\title{
Motivation an Important Part in Management
}

\author{
Qemajl Sejdija
}

The European University of Tirana, Faculty of Economics-Management, Albania

Email: qemaj@@sejdija.de

\section{Doi:10.5901/ajis.2016.v5n3s1p373}

\begin{abstract}
This paper elaborates definitions of motivation and describes several methods for employers to be trained by efforts to achieve the goals of the organization. The term motivation we understand the process that initiates, guides and maintains goal-oriented behaviors. They are some given methods of leadership that can inspired employees about their successes in the organization, the ability to hear, expressed, and respect the ideas and work of others establishing clear personal boundaries of responsibility and engagement on the development and creation of reports are clear between group of workers. One of the most important functions of management is to create willingness among employees to perform the best of their abilities. Individual and group performance means the impact of expression in order to achieve and to improve the results, including the activity that ensures the realization of the objectives on organizations. The main components that affect the motivation of work by leaders and workers, are: activation, - decision to start a purpose, persistence, - the constant effort towards a purpose and intensity concentration and energy that goes in pursuit of a goal. On the implementation of the study has been used analytical method by studying and analyzing the various theories of motivations studied in different periods of time, involvement by the influence of factors such as social factors, economic, cultural, and environmental factors all global circumstances and the changes made in the period of time. The main purpose of this study is to present methods in a systematic way affect the motivation of workers.
\end{abstract}

Keywords: motivation, leadership, performance, behavior, quality, purpose

\section{Introduction}

Motive is an important part through which the majority of workers reach the appropriate results. Understanding what motivates them is important in the workplace because people spend a significant part of their lives at work, so it is not surprising that they expect enjoy and get rewarded what they do.

They get more pleasure from their work, they miss less at work, they are more loyal, they work with enthusiasm, they are more encouraged to contribute more to development the enterprise.

Good manager with a clear vision it presents his values before certain groups, by which together they reach the objective and create favorable climate for employees and introducing values and work culture

These values of course will influence the behavior of workers within the workplace, making organization rather positive place, to have a good communication with each other and always relying on the strengths of the strategy of the organization but also of the employees

You should never force or threat an employee to perform a job, because this will not give him a motive to present and reached the right performance .The most important part of creating a positive work environment is, the role of manager

His role affects the creation of favorable work, they followed each time the progress of work, to intervene to employees through training while maintaining focus and be optimistic even when things do not go right, building confidence and bringing spirit to achieve realistic goals, remember you often achievements of the organization (not to mention the failures of the past)

Delivering the vision to others and joint contribution may be the greatest motivators for employees, since they will be introduced that are part of working together rather than special By this will be achieve their contribution and success of the organization by sharing their profits and give a chance and opportunities for stock for employees and the success of the company. Any well-planned goal of including employees in the proper positions and information, of course will achieve success after their include (workers) has been working since the beginning. However, what it is most important is that rewarded should not give without finishing work or achieve the intended result

Awards will be continued after the goals will achieve, and always be structured as feedback or ratings for their work

The research question in this study is: What are the leadership skills that motivate employees more than money? 
Ability to motivate employees is one of the greatest skills of an entrepreneur can possess

If organizations have fluctuations as by the management, control, delay of finance, etc. The concrete step to save the organization from a crisis is to engage individuals with appropriate experience, bringing organizational culture, improving and raising the morale of workers (especially when it comes to work hard) to create team that are passionate at work, etc.

Leadership abilities that affect the setting and motivation, that have contributed to achieve the common goal within the organization are:

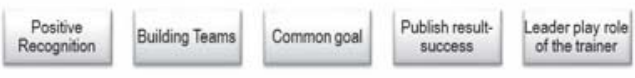

\section{Positive Recognition}

Recognition and evaluation of the performance of the employee by the employer can create a positive climate and new products in organization. Recognition of the work is one of the most powerful forms that can be provided to the employee, to achieve the right result, because it increases the positive feelings and affects on the achievement of confidence in the ability of his / her to do better work in organization

People who feel appreciated are more positive about themselves and their ability to contribute and potentially are best workers. Beliefs about knowledge of the work should be kept close to many organizations.

Many employers are loath to provide working knowledge because often they rely on time as evidence of knowledge of working in complaints, dissatisfaction, clarity, justice but also the quality and behavior of the worker.

To obtain new knowledge and continuous organization needs to establish criteria that makes a person eligible and contributing to better performance. If a person gets no reward or recognition for his work, will adversely affect his attitude and work connection

Recognition of work is also based on the situation.

Each individual has his preferences beneficial to this, during performance at work is very important to give the gratitude, because his work reflected on the benefit of the organization

Most of them do the job for money, as the best form for recognition the work. Therefore, there should also have any reward or bonus within or at the end of the diligent workers who deserve to be rewarded, which is one of the best ways to motivate employers

Table 1. Impact of positive recognition of the work in organization

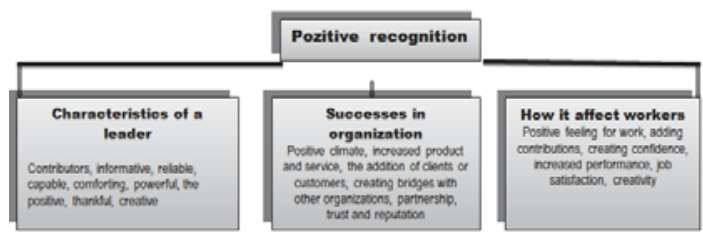

\section{Building Teams}

Building effective teams requires building social capital, which depends on how a team deals with emotion individual, group, and internal levels.

Each sector on organization would not be effective unless they were built work teams, which is a significant value that can be calculated rapidly changing requirements, labor market competition, etc. Building teams must always be in full harmony with the management to cope with the challenges during the working process. When working within the organization proceeded group, then teams thrive. Teamwork is vital, emotionally, intellectually, each time adapting common purpose within the organization's strategy

Promotion and evaluation processes, are structures that reflect the importance of team excellent

If the team glory, surely they are going to share good practice from both sides, in order to be given the chance of

Since early disregarding their recruitment should be taken correctly, but also to ensure continuity for receiving and 
exchanging of members in appropriate positions

Recruitment of new members may have the ability to challenge the leader, to play the role of team leadership. Team leadership role is very great, since you need to have the necessary energy, the conscious, driven by ego and in most cases equal to team members.

If the team during working hour is trying to do their job properly, the pressure from the leaders in this case should not be present

Simple cases that strengthen relationships in the team are: entertainment, holiday time, the organization of joint holidays, etc

Choosing and setting goals are the best ways to help the performance of workers, especially in achieving the financial goals that creates the possibility of sustainability of the organization that creates the possibility of sustainability of the organization

Table 2. Impact of building teams in the organization

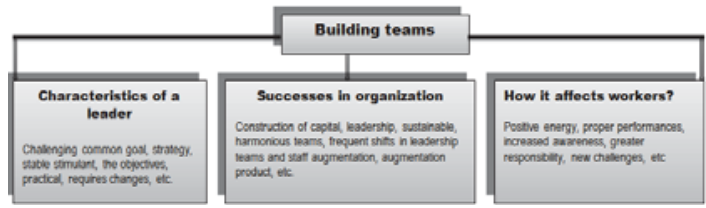

\section{Common Goal}

Work on the theory of goal setting suggests that is an effective tool for progress, ensuring that participants in a group with a common purpose, are clearly aware of what is expected of them

Setting goals helps people work in the right direction. As long as the individual accepts the goal, they have the ability to achieve it, and they don't have any conflict with goals

There is a positive relationship between goal difficulty and performance of duties

Conversations involve more trying to create unity around a common goal. The secret is to keep your ego in control and focusing on others.

Before the meetings begin, thanks the listeners that share their time with you, if you give space to express while the presentation, they will probably be more open, valued and included

Listening is the success of a successful communication

Before asking others to switch of the phone do it firstly, stay focused on what other people say about you. The word "absolute" should be avoided (use more rare), because it is difficult to keep

Table 3. Impact of common purpose in the organization

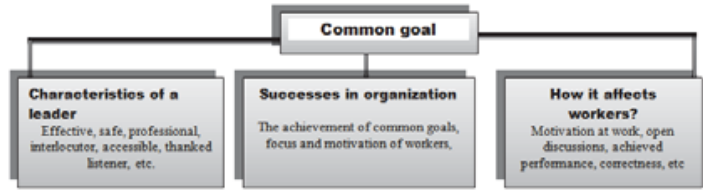

\section{Publish Result-Success}

Every successful business is successful if previously is planned.

Publication of success, firstly in the group summarizes: the best practices during implementation, achieved goals and how they managed, promotion, benefits, group and organization changes, in which principles is based on the realization (human resources and quality), actions positive, responsible, team performance, knowledge and used skills.

Success while conducting is: the agreements reached with associate and business expansion, the focus for investment and welfare, clear roles, networking and community communication, to recognize how to go, service for customers for product development, cooperation between interest parties in the future, tools for quality assessment and effectiveness of the work 
Table 4. Impact of the publication of results-success in organization

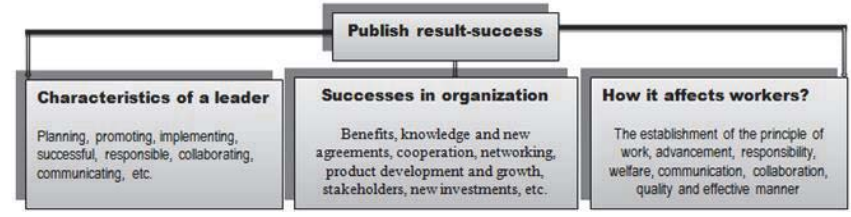

\section{Leader Play Role of the Trainer}

Leaders, to play the role of the coach in the organization, reach through the proper performance commitment, bringing innovation, build loyalty and productivity

To play this role, the leader must have certain characteristics, such as:

vision built to share with others, creating an environment to learn, be positive model, you know skills and values, to be honest-independent, to be/to have support from workers, not fear; be challenging and responsible, to encourage others to advocate a common leadership, to emphasize the common results.

These models transform the leaders through training to achieve positive steps, the exercise and strengthening of discussions and using their role as assistant, facilitator, partner, bypassing the role of "chief

Transformational leaders use and engage with interpersonal communication skills during their discussion, exercises, which affect positively to individual performance. Trainer, is the skill that can be learned and argue experiences through individual performance

Table 5. Impact of the leader and his role as a coach in the organization

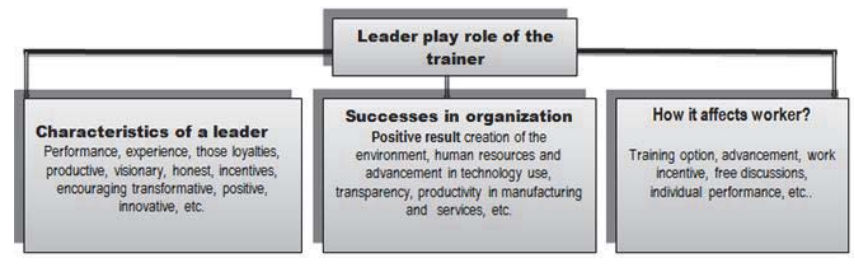

\section{Conclusion}

In this paper they are presented five methods of knowledge and influencing leaders to motivate employees and how to achieve the common goals of the organization. By: motivation, establishing basic needs of groups in the organization, confidence, self-fulfillment (using the skills and talents), recognition of the efforts and performance, the nature of selfemployment, responsibility, opportunity for improvement and promotion are based elementary very important that you submit a leader in practice and proper commitment will undoubtedly achieve the necessary results in the organization

According to numerous theories that are studied and analyzed for different styles of motivation, there are issue information which will be described below by presenting definitions of each method presented:

Positive- recognitions bring new breath in the organization, positively affect the quality, productivity and service quality. It creates freedom in action, additional workers, and partnership

Building teams - it affects on sustainable construction capital, alignment, easy in sharing and performance of duties, complicity, mutual communication, leisure time, etc

A common goal - It shows full responsibility as the leader of the group as well, proposals, results and success to date by both parties but also challenging as the aim to achieve requires sacrifice

Publish result -success - Present the achievements before groups (Leaving the country at the end of the presentation, and weakness) and begins the next stage of proposals and planning.

Leader play role of the trainer - primarily comes experience and knowledge of the leader then put into practice the right methods by creating more sustainable environment within the organization

The main purpose of this paper is to offer available data ,to be understandable, bringing information which can be 
used by many individuals to lead, which clearly don't know about methods that can be use to motivate employees and group to achieve the proper effect and result in the managerial field.

\section{References}

"How to Motivate Your Employees" Published May 10, 2012/ NewsCore (date: 08.11.2012), http://smallbusiness.foxbusiness.com/sbc /2012/05/10/how-to-motivate-your-employees/

Ilya Pozin "Inc" Nov 28, 2011 http://www.inc.com/ (Date:08.11.2012)

V. U. Druskat, S. B. Wolff, "The link between emotions and team effectiveness: how teams engage members and build effective task processes" Academy of Management Proceedings "99 OB: L1

Simon Hodiogton "“How to build an effective team", 28 JUNE 2007, p.46, www.peoplemanagement.co.uk/howto

http://en.wikipedia.org/wiki/Goal_setting(Date:05.12.2012)

Ch. St. Hilaire, http://www.beliefnet.com/Inspiration/2010/11/Work-Toward-Common-Goal.aspx (Date: 05.12.2012)

Pix Jonasson, CEO/ http://successdynamicsgroup.com/consulting/business-services(Date: 05.12.2012)

M.M.Starcevich, Ph. D" Coaching Behaviors of Transformational Leaders", http://www.coachingandmentoring.com /CoachingBehaviorsOfTransformationalLeaders.htm. (Date:05.12.2012)

Roger Darlington, "How to build a good team", 29 April 2006, http://www.rogerdarlington.me.uk/teamwork.html

Fred S. Drennan and David Richey, "Skills-Based Leadership",ProfessionalSafety March 2012 www.asse.org

W.H. Weiss, "Building morale, motivating, and empowering employees",

Diane Ciotta, "Improve Productivity: Identify Your Staff's Motivating Factors",

Chris Mussel white, "Creating a Culture of Motivation", T+D | September 2011,

Robbins/DeCenzo"Bazat e menaxhimit", chapter: 10 